\title{
Dynamic modelling of biomass gasification in a co-current fixed bed gasifier
}

\author{
Robert Mikulandrić ${ }^{1,2 *}$, Dorith Böhning ${ }^{3}$, Rene Böhme $^{3}$, Lieve Helsen ${ }^{4}$, Michael Beckmann ${ }^{3}$, Dražen Lončar ${ }^{1}$
}

1. Department of Energy, Power Engineering and Ecology, Faculty of Mechanical Engineering and Naval

Architecture, University of Zagreb, No.5 Ivana Lučića, 10002 Zagreb, Croatia

2. Department of Biosystems, Faculty of Bioscience Engineering, KU Leuven, No. 30 Kasteelpark Arenberg,

3001 Leuven, Belgium

3. Institute of Power Engineering, Faculty of Mechanical Science and Engineering, Technical University

Dresden, No. 3b George-Bähr-Strasse, 01069 Dresden, Germany

4. Department of Mechanical Engineering, Faculty of Engineering Science, KU Leuven, No. 300

Celestijnenlaan, 3001 Leuven, Belgium

e-mail: robert.mikulandric@fsb.hr; dloncar@fsb.hr; michael.beckmann@tu-dresden.de;

Lieve.Helsen@kuleuven.be

\begin{abstract}
Existing technical issues related to biomass gasification process efficiency and environmental standards are preventing the technology to become more economically viable. In order to tackle those issues a lot of attention has been given to biomass gasification process predictive modelling. These models should be robust enough to predict process parameters during variable operating conditions. This could be accomplished either by changes of model input variables or by changes in model structure. This paper analyses the potential of neural network based modelling to predict process parameters during plant operation with variable operating conditions. Dynamic neural network based model for gasification purposes will be developed and its performance will be analysed based on measured data derived from a fixed bed biomass gasification plant operated by Technical University Dresden (TU Dresden). Dynamic neural network can predict process temperature with an average error less than $10 \%$ and in those terms performs better than multiple linear regression models. Average prediction error of syngas quality is lower than $30 \%$. Developed model is applicable for online analysis of biomass gasification process under variable operating conditions. The model is automatically modified when new operating conditions occur.
\end{abstract}

Keywords: Biomass gasification, dynamic modelling, artificial neural networks, fixed bed gasifiers

*corresponding author 


\begin{tabular}{|c|c|c|c|}
\hline \multicolumn{4}{|c|}{ Nomenclature } \\
\hline \multicolumn{2}{|c|}{ Main symbols } & \multicolumn{2}{|c|}{ Abbreviations } \\
\hline mair & air flow rate, $\mathrm{m}^{3} / \mathrm{h}$ & ANN & artificial neural networks \\
\hline mair $_{a v}$ & average air flow rate, $\mathrm{m}^{3} / \mathrm{h}$ & APE & average prediction error \\
\hline$m b$ & biomass flow rate, $\mathrm{kg} / \mathrm{h}$ & $\mathrm{CH}_{4}$ & methane \\
\hline$m b_{a v}$ & average biomass flow rate, $\mathrm{kg} / \mathrm{h}$ & $\mathrm{CO}$ & carbon monoxide \\
\hline$m b_{\text {freq }}$ & fuel injection frequency, - & $\mathrm{CO}_{2}$ & carbon dioxide \\
\hline error $_{a v}$ & average error, - & $\mathrm{H}_{2}$ & hydrogen \\
\hline$\beta_{1-10}$ & regression coefficients, - & MFB & mean fractional bias \\
\hline$i$ & measurement number, - & MLR & multiple linear regression \\
\hline $\mathrm{N}$ & number of measurement samples, - & NMBF & normalised mean bias factor \\
\hline$T$ & temperature, ${ }^{\circ} \mathrm{C}$ & NNM & neural network model \\
\hline \multirow[t]{3}{*}{$t$} & time & $\mathrm{O}_{2}$ & oxygen \\
\hline & & $\mathrm{R}^{2}$ & coefficient of determination \\
\hline & & RMSE & root mean square error \\
\hline
\end{tabular}

\section{INTRODUCTION}

The process of biomass gasification is a high-temperature partial oxidation process in which a solid carbon based feedstock is converted into a gaseous mixture $\left(\mathrm{H}_{2}, \mathrm{CO}, \mathrm{CO}_{2}, \mathrm{CH}_{4}\right.$, light hydrocarbons, tar, char, ash and minor contaminants) called 'raw syngas', using gasifying agents [1]. Gasification products are mostly used for separate or combined heat and power generation [2], for hydrogen production [3], methanol production [4] and production of other chemical products [5]. A more detailed overview of available biomass gasification technologies is published by Kirkels and Verbong [5].

Although, gasification is a relatively well known technology, the share of gasification in overall energy demand is small due to current barriers concerning biomass harvesting and storage [6], biomass pre-treatment (drying, grinding and densification), gas cleaning (physical, thermal or catalytic), process efficiency and syngas quality issues [7]. The performance of biomass gasification processes is influenced by a large number of operational 
parameters, among them: biomass quality, fuel and air flow rate, composition and moisture content of the biomass, gasifier design, reaction/residence time, gasifying agent, biomass particle sizes, gasification temperature and pressure [8]. Process temperature is considered as one of the most important process parameters which influences syngas quality, reaction rate and tar concentration [9]. Furthermore, gasification operating conditions have tendency to change during a long term facility operation due to ash sintering, agglomeration and deposition on reactor walls which could cause bed sintering and defluidisation [10].

To improve process efficiency or to guarantee constant process quality during operation, plant operation simulation models that enable parameter prediction as a function of various operating conditions, are needed. Large scale experiments could be used for this purpose on pilot plants [11] or laboratory scale setups [12] but they are often too expensive or problematic in terms of safety. Most of the available models for biomass gasification simulation are based on equilibrium models for Gibbs free energy minimisation [13], CFD analysis [14] or kinetic reactions [15]. A more detailed review of available models for biomass gasification process can be found in the research done by Baruah and Baruah [16] or in comparative analysis performed by Mikulandric et al. [17]. From this point of the state of the art, it can be concluded that the most of available models are well capable to describe stationary process behaviour under constant operating conditions but they are not suitable for on-line process analysis where process dynamics under changeable operating conditions is considered.

Adaptable/evolutionary models and optimisation methods have potential to become a powerful methodology for gasification systems analysis, control and optimisation [18]. Artificial intelligence systems (such as neural networks) are widely accepted as a technology that is able to deal with non-linear problems, and once trained can perform prediction and generalization at high speed. Artificial neural network (ANN) based prediction models use a non-physical modelling approach which correlates the input and output data to develop a process prediction model. ANN is a universal function approximator that has the ability to approximate any continuous function to an arbitrary precision even without a priori knowledge about the structure of the function that is approximated [19]. Dynamic neural networks with feedforward or recurrent feedback connections are used for systems with large delays like activated sludge processes [20], vapour-compression liquid chillers [21], chemical process systems [22] or energy related prediction processes [23]. Once trained ANN can predict process parameters in circulating and bubbling fluidised bed gasifiers [24], fluidised bed gasifiers with steam as gasifying agent [25] or in fixed bed gasifiers [26] with reasonable speed and accuracy. However, the prediction quality of trained ANN is 
highly dependent on the quantity and quality of training data related to the process. Changing process operating conditions can cause large prediction errors if the ANN models have not been modified for those particular conditions. The importance of dynamic modelling has been elaborated for the case of flexible operation and optimisation of carbon dioxide capture plants [27]. To encounter issues related to changeable operating conditions and to obtain reasonable model prediction accuracy Wang and $\mathrm{Hu}$ [28] proposed a dynamic parameter estimation approach using genetic algorithms to predict thermal behaviour of buildings with changeable thermal capacitance. For prediction of the lead-acid battery state of charge during operation Fendri and Chaabene [29] proposed dynamic recursive estimation Kalman filter algorithms. However, performance of a dynamic modelling approach for changeable operating conditions in biomass gasification has still not been analysed.

In this paper a dynamic ANN based modelling approach will be utilised to describe the process behaviour in a $75 \mathrm{~kW}_{\text {th }}$ fixed bed gasifier, operated by TU Dresden. The ANN model needs to be able to predict process parameters with reasonable speed and accuracy in a gasification process with large delays and changing operating conditions. In order to guarantee prediction accuracy for changing operating conditions a dynamic modelling approach with automatic ANN re-training sessions will be utilised and its performance will be compared with a dynamic multiple linear regression based model. Reasonable prediction speed is required in order to enable on-line parameter prediction for process analysis. Model performance has been analysed using statistical error analysis.

\section{GASIFICATION PLANT AND OPERATING CONDITIONS}

In order to develop a neural network based model (NNM), the neural network has to be trained using observed/measured data to predict process parameters. Neural network based models generally require a large number of measurement data to form input and output data sets for neural network training. Results from NNM could differ significant if different sets of input and output data have been used for training purposes. Due to their nature NNMs are used to describe particular processes that occur in the observed system during stable operating conditions. However, if something changes in the process due to changes in operating conditions, design changes, biomass quality or other unexpected process variables the NNM structure has to be modified (NNM has to be retrained) to preserve prediction quality for this particular condition. For the purpose of NNM modelling 2 sets of experiments ( 9 experiments in total), with different operating conditions, were conducted to form a database for NNM training. The object of modelling is a co-current fixed bed gasifier with thermal input of $75 \mathrm{kWth}$, located 
in Pirna (Germany), operated by TU Dresden. Biomass wood chips, distributed from a local provider, are used as fuel in the gasification process. The facility scheme is presented in Fig. 1.

During facility operation the biomass is firstly injected manually in a small storage room with a manually controlled valve. Once the valve opens, the whole amount of biomass from the storage room is injected into the biomass shredder and consequently injected into the gasification reactor. Gasification air is distributed by fans and injected in the process from the upper side of the gasifier, leading to a co-current flow system. Ash is removed manually by opening ash removal valves. The biomass quality could be determined offline by dedicated laboratory tests, however it is hard to determine biomass quality for modelling purposes online due to variability between batches of distributed wood chips.

Two sets of experiments were performed to analyse the process behaviour. The first set of 4 experiments (Experiments 1-4) were performed in 2006 and resulted in more than 40 hours of operation. The second set of 5 experiments (Experiments 5-9) were performed in 2013 and resulted in more than 35 hours of operation. Experiments were performed to determine/measure following process parameters: biomass mass flow rate $(\mathrm{mb})$; air volume flow rate (mair); syngas temperature at the exit of the gasifier; syngas composition; pressure in the reactor and temperature of inlet air. All data was recorded on a 30 seconds base in accordance with relevant international standards for this type of measurements. The measurement equipment for dedicated tests is listed in Table 1.

After measurements, the data was analysed in order to define a set of input and output datasets for NNM training after which the data was pre-processed. For the process temperature prediction the average biomass fuel flow rate was averaged on 25 minutes basis, together with the air flow rate (Eq 1 and 2). Injection frequency (the time from the last fuel injection) was also calculated to incorporate the dynamic behaviour (delays) of the process (instead of using a dynamic neural network modelling approach). A detailed description of the data analysis and motivation for this particular data analysis approach are presented in [26]. Results of data analysis for fuel flow rate, air flow rate and fuel injection frequency for Experiments 1-4 (2006) and 5-8 (2013) are presented in Figures 2, 3 and 4. $m b_{a v}=\int_{t=i-25}^{t=i} m b d t$

mair $_{a v}=\int_{t=i-25}^{t=i}$ mair $d t$ 
During Experiments 1-4 the amount of the injected biomass (fuel) is in general less than during Experiments 5-8. This could be due to different biomass quality, plant ageing, ash agglomeration or due to some other unwanted changes in the gasifier. Furthermore, the profile of the fuel flow rate has been changed. While in Experiments 1-4 the fuel injection rate is quite constant (can be seen from time without fuel injection diagrams) in Experiments 58 the fuel injection rate is more scattered during gasifier operation and can reach up to 20 minutes without fuel injection (while in Experiments 1-4 the time without fuel injection is generally less than 7 minutes). Generally, more fuel in a more dispersed way has been injected during Experiments 5-8 in comparison to Experiments 1-4. Air injection rate profiles are rather constant in all experiments and range between 10 and $15 \mathrm{~m}^{3} / \mathrm{h}$. It is reasonable to assume that due to changes in fuel flow rate and fuel injection frequency the process will behave in a different way which will result in different temperature profiles (together with other process parameters).

\section{MODELLING METHODS}

For modelling purposes data collected from Experiments 1-9 has been used to form a database for NNM training. For artificial neural-network (ANN) based prediction models the adaptive network-based fuzzy inference system (ANFIS) with Suggeno type of fuzzy model and hybrid learning algorithms with 27 nodes (together with membership functions) in structure layers were used. The individual Multi Input Single Output system comprises of 4 inputs (fuel flow rate, fuel injection frequency, air flow rate and current temperature of syngas at outlet) and one output which represents the temperature change. A simple analysis for different number of iterations for NNM training has been performed with 10, 25, 50 and 100 iterations. The prediction quality after 50 iterations did not improve considerably so due to a shorter computational time and to reduce the risk of NNM overfitting the NNM model with 50 iterations has been chosen. The change in syngas outlet temperature (to be considered as process temperature in the further text) was set as model output. Syngas temperature was then determined by integration of predicted temperature changes. With this approach the process dynamics related to process temperature can be described in a qualitative way [26]. Dynamic neural network models with feedforward or recurrent feedback connections could be used for the same purpose but due to limitations of this approach in terms of automatic online analysis in MATLAB software, a general scheme that is presented in Figure 5 has been used.

The NNM model was initially trained on data derived from Experiments 1-4. Detailed training results can be found in [26]. For the trained cases, the ANN temperature prediction model shows good correlation with measured data 
[26]. After the model was initially developed based on data from Experiments 1-4 it has been applied to predict process temperature for Experiments 5-9. As discussed in the previous section, the process conditions in Experiments 5-9 have changed considerably in comparison with the conditions from Experiments 1-4 due to unknown reasons. Therefore it is shown later in the paper that the developed NNM has larger prediction errors than in the cases from Experiments 1-4.

A similar methodology has been applied to predict gas composition $\left(\mathrm{H}_{2}, \mathrm{CH}_{4}\right.$ and $\left.\mathrm{CO}\right)$ during operation. The combination of fuel flow rate, fuel injection frequency, air flow rate and current temperature of syngas at outlet as input for NNM provided the best prediction results in the previous study [26] and therefore those inputs were considered again for the development of a dynamic model for syngas composition prediction.

In order to mitigate the effects of changing operating conditions on the NNM prediction performance a dynamic modelling approach is proposed. First, the NNM is trained on existing data from Experiments 1-4. The same model is initially applied to predict the process temperature in different process conditions (Experiments 5-9). Prediction error (defined by Eq. 3) is continuously analysed (error value can range between -1 and $+\infty$ ) in order to preserve prediction quality of the model. When the average error (defined by Eq.4) between predicted and measured values in the last 50 minutes exceeds the defined average error tolerance threshold (in the presented case the defined average error tolerance threshold is set to be $10 \%$ ) then the trigger for re-modelling is turned on. The trigger enables re-training of the NNM based on a newly formed database (old database extended with new measurements up to that moment). After re-training, the error tolerance is temporary increased to $\pm 100 \%$ for the next 3 minutes in order to prevent fast trigger resetting after NNM re-modelling (constant re-training will result in extensive time loss). After re-training the predicted temperature is set to the last measured value. This modelling methodology is presented in Figure 6.

$$
\begin{aligned}
& \text { error }=\frac{T_{\text {predicted }}-T_{\text {measured }}}{T_{\text {measured }}} \\
& \text { error }_{a v}=\frac{\int_{t=i-50}^{t=i} \mid \text { error } \mid d t}{50}
\end{aligned}
$$

For additional model performance analysis, temperature predictions from developed NNM have been compared to temperature predictions of Multiple Linear Regression (MLR) models. 2 different MLR models have been utilised for analysis. General form of first (MLR1) model is given in Eq. 5 while general form of second (MLR2) 
model is given in Eq. 6. During analysis MLR models will follow the same procedure for model re-training as for NNMs. Similar analysis approach can be found in the research performed by Vlachogianni et al [30].

$$
\begin{aligned}
& \Delta T=\beta_{0}+\beta_{1} \cdot m b_{a v}+\beta_{2} \cdot \text { mair }_{a v}+\beta_{3} \cdot m_{\text {freq }}+\beta_{4} \cdot T \\
& \Delta T=\beta_{0}+\beta_{1} \cdot m_{a v}{ }^{2}+\beta_{2} \cdot \text { mair }_{a v}{ }^{2}+\beta_{3} \cdot \mathrm{mb}_{\text {freq }}{ }^{2}+\beta_{4} \cdot T^{2}+\beta_{5} \cdot m b_{a v} \cdot \text { mair }_{a v}+\beta_{6} \cdot m b_{a v} \cdot m b_{\text {freq }}+ \\
& \beta_{7} \cdot m b_{a v} \cdot T+\beta_{8} \cdot \text { mair }_{a v} \cdot m_{\text {freq }}+\beta_{9} \cdot \text { mair }_{a v} \cdot T+\beta_{10} \cdot m b_{\text {freq }} \cdot T
\end{aligned}
$$

To analyse models performance in terms of error metrics the coefficient of determination $\left(\mathrm{R}^{2}\right)$, root mean square error (RMSE), average prediction error (APE), mean fractional bias (MFB) and the normalised mean bias factor (NMBF) metrics have been calculated. Coefficient of determination is the most commonly used technique to evaluate model fitting performance. However, it is used for linear models and it does not provide the information related to an average prediction error. In order to quantify average model prediction error the root mean square error and user defined average prediction error analysis has been performed. User defined average prediction error derived from Eq 3 presents prediction error in a way that can be easily interpreted by plant operator during plant operation. In order to analyse model prediction bias the mean fractional bias and normalised mean bias factors have been calculated. Although mean fractional bias has been commonly used [31], the normalised mean bias factor metrics can evaluate model over- and under-prediction more proportionally [31]. Related equations (Eq. 6Eq.10) for statistical analysis of temperature prediction model are following:

$$
\begin{aligned}
& R^{2}=1-\frac{\sum_{t=0}^{t=i}\left(T_{\text {measured }}-T_{\text {predicted }}\right)^{2}}{\sum_{t=0}^{t=i}\left(T_{\text {measured }}-T_{\text {mean }}\right)^{2}} \\
& R M S E=\sqrt{\frac{\sum_{t=0}^{t=i}\left(T_{\text {measured }}-T_{\text {predicted }}\right)^{2}}{N}} \\
& A P E=\frac{\sum_{t=0}^{t=i}\left|\frac{T_{\text {predicted }}-T_{\text {measured }}}{T_{\text {measured }}}\right|}{N} \\
& M F B=\frac{1}{N} \sum_{t=0}^{t=i} \frac{T_{\text {predicted }}-T_{\text {measured }}}{\frac{T_{\text {predicted }}+T_{\text {measured }}}{2}} \\
& N M F B=\frac{\sum_{t=0}^{t=i} T_{\text {predicted }}-\sum_{t=0}^{t=i} T_{\text {measured }}}{\left|\sum_{t=0}^{t=i} T_{\text {predicted }}-\sum_{t=0}^{t=i} T_{\text {measured }}\right|}\left[\exp \left(\left|\ln \frac{\sum_{t=0}^{t=i} T_{\text {predicted }}}{\sum_{t=0}^{t=i} T_{\text {measured }}}\right|\right)-1\right]
\end{aligned}
$$




\section{RESULTS AND DISCUSSION}

The performance of the developed dynamic modelling approach has been analysed using 9 different experiments. The first 4 experiments (conducted in 2006) were utilised as initial data for the NNM development. Experiments 5-9 were used to simulate a real-time plant operation after a change in the plant's operating conditions due to unknown reasons. Measurements from Experiments 5-9 have been added sequentially to the database so that the algorithm for the ANN model training and re-training can use only data collected prior to model re-training (NNM re-training algorithms do not have prior knowledge of other experiments). Online model performance has been evaluated and monitored using Eq. 3.

Results derived from the NNM that has been trained only with the initial database from Experiments 1-4 are presented in Figure 7. Some values are missing due to practical reasons (they are too large to be fitted in a graph). The Figure shows that the NNM that has been trained only with the initial database has no ability to predict process temperatures during Experiments 5-9 (after process conditions have been changed). For Experiments 5 and 8 the model predicted temperature is unrealistically high so the prediction error is more than $150 \%$. The calculated prediction error is higher than $100 \%$ due to nature of equation that has been used for online model prediction error estimation (Eq. 3). In some cases the prediction error (difference between predicted and measured value) is larger than the measured temperature itself which results in prediction errors that are larger than $100 \%$. For experiment 7 predicted temperatures are much lower than measured values. Measured temperatures in Experiments 5,8 and 9 are lower than temperatures in Experiments 1-4 due to unknown changes in process operating conditions so the predicted temperature values in Experiments 5,8 and 9 with the NNM structure from Experiments 1-4 are generally higher. Even in Experiments 6 and 9 where predicted temperatures are more or less realistic the absolute prediction error is mostly above $50 \%$. One way to reduce the prediction error could be to continuously change NNM model structure (type of neural network or the number of hidden layers) in order to have a better prediction quality for all experiments. However, a changing NNM structure would result in a large engineering effort during plant operation. Therefore, this approach would be unpractical for on-line process analysis. Approach that has been proposed in 'Modelling methods' section (that uses an automatic approach to adjust the prediction model) should be able to modify the model in a way that is more appropriate for on-line process analysis. 
After the initial analysis with the NNM that has been trained with the original database only, the developed dynamic modelling methodology is applied to analyse its performance. As in the previous case, the NNM was initially trained with the existing database from Experiments 1-4 in order to have a base for prediction purposes. After initial training the model is utilised to predict the process temperature (syngas outlet temperature) after a change in operating conditions (starting from Experiment 5). The same database as in the previous case is used to analyse the potential of the dynamic ANN modelling approach. Different average prediction error tolerances are used to analyse the sensitivity (in terms of prediction quality and speed) of the modelling approach. It is clear that higher error tolerance threshold enables faster parameter prediction due to smaller number of re-training sessions but reduces prediction quality. Results of the sensitivity analysis are presented in Table 2 .

Results derived from the developed dynamic NNM approach with an average error tolerance threshold of $50 \%$ are presented in Figure 8. Although the prediction potential of the developed dynamic NNM is improved compared to the previous case, the prediction error is still very high (around $\pm 30 \%$ on average). The largest prediction error appears in Experiment 6. Although the prediction error is high, due to a large error tolerance threshold (50\%) the re-training session is triggered only 200 minutes after last re-training session. Nevertheless, the predicted values differ significantly from the measured ones. The sensitivity analysis suggests that the error tolerance threshold should be significantly reduced in order to improve prediction quality.

The results derived from the dynamic NNM with error tolerance threshold of $10 \%$ are presented in Figure 9. With the proposed dynamic modelling approach the prediction error has been reduced significantly. The prediction error is mostly within $\pm 20 \%$ but can reach up to $80 \%$ for the time periods just before re-training. After re-training the prediction error is generally reduced for the time periods close to re-training points, which is the result of setting the prediction temperature to the last measured value after re-training but it is also due to a new NNM structure that has been re-trained with the newly extended database. In most cases, the tendency of error increase after retraining is lower than before re-training.

Re-training sessions are marked with a black line in the prediction error graphs. After the changes in operating conditions have occurred (at the beginning of Experiment 5) the error tolerance threshold is triggered very often in the first 200 minutes of plant operation. This is due to large prediction errors that occur in the first 200 minutes of plant operation. High prediction errors result from changes in operating process conditions in combination with an NNM structure that is inappropriate for these particular operating conditions. Therefore, the algorithms try to 
find an appropriate NNM structure by using a high frequency of re-training sessions in the first minutes of operation. However, due to insufficient data quantity for a qualitative NNM structure, the prediction error is still high and re-training sessions occur quite often in that period. After the model has been trained with sufficient data, that is relevant to the current process, the prediction error is reduced together with the frequency of re-training sessions. The same effect can be seen at the beginning of Experiment 6 . Retraining sessions occur frequently in the beginning but after 200min (when sufficient model training data related to the current process has been collected) the frequency of re-training is reduced. In experiment 7 the developed NNM is able to predict temperatures with reasonably good accuracy so the number of retraining sessions is significantly reduced. A similar behaviour can be seen in Experiment 9.

Additional analysis allows investigating the influence of the amount of data for each re-training session on the prediction performance of the dynamic model. 5 different cases were analysed. In the first case the data from the last 1000 minutes has been used for model re-training. In the other cases the data from the last 1500, 2000 and 2350 minutes as well as all the available data has been used. Analysis has been performed based on $30 \%$ error threshold. With a larger dataset the average prediction error can be decreased together with the number of required re-training sessions. Although a larger amount of data for re-training will require more computational power and time for each individual re-training session the reduced number of required re-training sessions could reduce overall time for model development. Analysis results are presented in Table 3.

For the dynamic ANN model development a computer configuration that comprises of an i7-3820 processor with $3.60 \mathrm{GHz}$ and $64 \mathrm{~GB}$ of RAM memory has been used. 4 minutes are necessary to predict the process temperature for Experiments 5-9 with the dynamic NNM approach in the way that is presented in this paper using a tolerance threshold of $10 \%$ (26 re-training sessions in total). Around 10 seconds are necessary for one re-training session. That enables re-training between 2 measurements (measurement sampling frequency is 30 seconds). Therefore, the proposed approach can be used for on-line process temperature prediction in a dynamic environment where operating conditions change due to unknown reasons.

After it has been concluded that developed NNM is well capable to predict process temperature with required speed and reasonable accuracy the temperature prediction results were compared with developed dynamic MLR models. For the analysis the threshold has been set to $10 \%$ and all the data has been utilised for model re-training 
sessions. Performance analysis results have been summarised in Table 3. Dynamic MLR1 has a higher prediction error than MLR2 model. However, dynamic NNM has the smallest prediction error of temperature prediction for an observed case. The number of re-training sessions is the smallest in the case of MLR2 model while the highest in the case of NNM. Dynamic MLR models are much faster in terms of process temperature prediction and retraining time but due to fact that the prediction speed and the time for a re-training session of NNM is below sampling time the advantage has been given to prediction accuracy. A detailed performance analysis of developed models has been presented in Figure 10 .

Based on the proposed methodology for NNM development dynamic syngas composition models $\left(\mathrm{H}_{2}, \mathrm{CH}_{4}\right.$ and CO) have been developed and their potential has been analysed based on Experiments 1-8. The data from Experiment 9 does not include syngas composition measurements and therefore this experiment will not be considered. In general dynamic models for estimation of syngas composition require much more retraining sessions than dynamic models for temperature prediction to obtain reasonable prediction quality. This is due to a more complex processes related to syngas production but also due to the sensitivity of measurement equipment and measurement error. For a more detailed analysis of syngas composition model prediction potential, measurements with more accurate measurement equipment should be obtained.

Simulation results are presented in Figure $11\left(\mathrm{H}_{2}\right)$, Figure $12\left(\mathrm{CH}_{4}\right)$ and Figure $13(\mathrm{CO})$. Error prediction threshold has been set to $30 \%$ in order to reduce the frequency of re-trainings and to make representation of results more practical. Although the prediction error during Experiments 5-8 is relatively high $\left(26.4 \%\right.$ for $\mathrm{H}_{2}, 38.3 \%$ for $\mathrm{CH}_{4}$ and $29.9 \%$ for $\mathrm{CO}$ ) the re-training frequency is decreasing during plant operation together with the average prediction error. This is the result of a new NNM structure that has been developed during plant operation using re-training sessions. It must be noted that the number of available data for syngas prediction model training is much smaller (900 minutes of available data) than in the case for temperature prediction model (2300 minutes of available data) and it does not cover all temperature ranges (only between $200^{\circ} \mathrm{C}$ and $300^{\circ} \mathrm{C}$ ). An increase of the number of available data will definitely contribute to a better model performance. Furthermore, a decrease of error prediction threshold would improve prediction quality but also the required re-training time. Although a large number of re-trainings were needed for an online dynamic modelling (around 100 for 900 minutes of operation) the total re-training time lasts less than 15 minutes in total. One re-training session takes around 7.5 seconds which 
enables model modification between two measurements. The summary of the dynamic model performance (related to syngas composition prediction) for the applied prediction error threshold of $30 \%$ is presented in Table 5 .

The summary of statistical model prediction performance analysis is presented in Table 6 . The best result is obtained in the case where the temperature prediction model has been developed with a $10 \%$ error tolerance threshold with all the data for model training. The model has the lowest root mean square error and average prediction error. Furthermore, the model results in a low (in absolute terms) and positive bias which means that the model predictions are generally close to the correct value with a slight over-prediction. With reducing error tolerance threshold the root mean square error, the average prediction error and model bias factor decrease. With improving the size of database for re-training model's root mean square error and average prediction error decrease but there is no general conclusion related to model bias.

Both developed models (the one for temperature and the one for syngas composition) have potential to be implemented in the proposed system with measurement frequency of 30 seconds. The time between 2 measurements is enough for the algorithms to collect the data, to analyse the data and to modify the existing model. Temperature prediction error can be kept around $10 \%$ with the proposed methodology while syngas prediction error can be kept around $30 \%$ on average. Therefore, the model is well capable of predicting syngas temperature and syngas composition with reasonable accuracy and under changing operating conditions. The proposed methodology seems to be a promising approach to model gasification process for different biomass types or different gasification fuels (coal or sludge). However, a related research should be performed in order to analyse the performance of those model types. For a more detailed analysis of the proposed methodology to predict syngas quality a more robust and accurate measurements set-up is needed.

\section{CONCLUSION}

For the purpose of temperature and syngas composition prediction in a $75 \mathrm{~kW}_{\text {th }}$ gasification plant a dynamic artificial neural network modelling approach has been applied. Artificial neural networks have a good potential to approximate process parameters in a highly nonlinear processes but they are sensitive to the quality and the quantity of training data that is available. If the training data for neural network model development does not correspond to current process behaviour the prediction error of the model will be high. Therefore, progressive 
modifications in the neural network model structure are needed during plant operation. The proposed approach for dynamic artificial neural network modelling comprises of an on-line prediction error analysis that enables on-line neural network re-training in order to preserve parameter prediction quality. Developed dynamic neural network model is able to predict process temperature and syngas composition with reasonable accuracy and speed that allows on-line analysis in changeable operating conditions. It performs better in terms of temperature prediction accuracy than multiple linear regression models. The average process temperature prediction error of the proposed dynamic artificial neural network model is $7.06 \%$ during more than 70 hours of plant operation while the syngas composition prediction error is around $30 \%$. The associated neural network re-training time of 10 seconds enables on-line prediction quality analysis and neural network model structure modifications. Proposed methodology seems to be a promising approach to model particular gasification process for different fuel types under changeable operating conditions.

\section{ACKNOWLEDGEMENTS}

This paper has been created within the international scholarship programme financed by DBU (Deutsche Bundesstiftung Umwelt) in cooperation among partners from Institute of Power Engineering, Faculty of Mechanical Science and Engineering, Technical University Dresden (Germany) and Department of Energy, Power Engineering and Ecology, Faculty of Mechanical Engineering and Naval Architecture, University of Zagreb (Croatia), with the support of the Mechanical Engineering Department of KU Leuven. 


\section{REFERENCES}

[1] Ahmed T, Ahmad M, Yusup S, Inayat A, Khan Z. Mathematical and computational approaches for design of biomass gasification for hydrogen production: a review. Renewable and Sustainable Energy Reviews 2012; 16 : $2304-15$.

[2] Adams PWR, McManus MC. Small-scale biomass gasification CHP utilisation in industry: Energy and environmental evaluation. Sustainable Energy Technologies and Assessments 2014; 6: 129-40.

[3] Kirtay E. Recent advances in production of hydrogen from biomass. Energy Conversion and Management 2011; 52: 1778-89.

[4] Holmgren K, Andersson E, Berntsson T, Rydberg T. Gasification-based methanol production from biomass in industrial clusters: Characterisation of energy balances and greenhouse gas emissions. Energy 2014; 69: 622637.

[5] Kirkels A, Verbong G. Biomass gasification: Still promising? A 30-year global overview. Renewable and Sustainable Energy Reviews 2011; 15: 471-81.

[6] Fowler P, Krajacic G, Loncar D, Duic N. Modeling the energy potential of biomass $-\mathrm{H}_{2}$ RES. International Journal of Hydrogen Energy 2009; 34: 7027-7040.

[7] Ruiz JA, Juarez MC, Morales MP, Munoz P, Mendivil MA. Biomass gasification for electricity generationReview of current technology barriers. Renewable and Sustainable Energy Reviews 2013. 18; 174-83.

[8] Boerrigter H, Rauch R. Review of applications of gases from biomass gasification. Netherlands: Biomass Technology Group; 2005.

(http://85.25.64.83/docs/Gasifiers/Review_Applications_Of_Gases_From_Biomass_Gasification_2006.pdf)

[9] Taba LE, Irfan MF, Daud WAM, Chakrabarti MH. The effect of temperature on various parameters in coal, biomass and Co-gasification: a review. Renewable and Sustainable Energy Reviews 2012; 16: 5584-96.

[10] Wang L, Weller C, Jones D, Hanna M. Contemporary issues in thermal gasification of biomass and its application to electricity and fuel production. Biomass and Bioenergy 2008; 32: 573-581

[11] Siedlecki M, Jong W. Biomass gasification as the first hot step in clean syngas production process - gas quality optimization. Biomass \& Bioenergy 2011. 35; S41-S62.

[12] Moghadam RA, Yususp S, Azlina W, Nehzati S, Tavasoli A. Investigation on syngas production via biomass conversion through the integration of pyrolysis and air-steam gasification processes. Energy Conversion and Management 2014. 81; 670-75. 
[13] Cohce MK, Dincer I, Rosen MA. Thermodynamic analysis of hydrogen production from biomass gasification. International Journal of Hydrogen Energy 2010; 35: 4970-4980.

[14] Silva V, Rouboa A. Combining a 2-D multiphase CFD with a Response Surface Methodology to optimize the gasification of Portugese biomasses. Process simulation of biomass gasification in a bubbling fluidised bed reactor. Energy Conversion and Management 2015; 99: 28-40.

[15] Beheshti SM, Ghassemi H, Shahsavan-Markadeh R. Process simulation of biomass gasification in a bubbling fluidised bed reactor. Energy Conversion and Management 2015; 94: 345-352.

[16] Baruah D, Baruah DC. Modeling of biomass gasification: A review. Renewable and Sustainable Energy Reviews 2014; 39: 806-815.

[17] Mikulandric R., Loncar D., Böhning D., Böhme R. Biomass gasification modelling aspects, In: Proceedings of the 13th International Conference on Polygeneration Strategies (Vienna, Austria, 2013).

[18] Nougues JM, Pan YG, Velo E, Puigjaner L. Identification of a pilot scale fluidised-bed gasification unit by using neural networks. Applied thermal Engineering 2000; 20: 1564 - 75.

[19]Puig-Arnavat M, Bruno J, Coronas A. Review and analysis of biomass gasification models. Renewable and Sustainable Energy Reviews 2010; 14: 2841-2851

[20] Cote M, Grandjean B, Lessard P, Thibault J. Dynamic modelling of the activated sludge process: Improving prediction using neural networks. Water Research 1995; 29: 995-1004.

[21] Bechtler H, Browne MW, Bansal, Kecman V. New approach to dynamic modelling of vapour-compression liquid chillers: artificial neural networks. Applied Thermal Engineering 2001; 21: 941-953.

[22] Bhat N, McAvoy TJ. Use of neural nets for dynamic modelling and control of chemical process systems. Computers Chemical Engineering 1990; 14: 573-583.

[23] Rotich N, Backman J, Linnanen L, Daniil P. Wind Resource Assessment and Forecast Planning with Neural Networks. Journal of Sustainable Development of Energy, Water and Environment Systems 2014; 2: 174-190. [24]Puig-Arnavat M, Hernandez A, Bruno JC, Coronas A. Artificial neural network models for biomass gasification in fluidized bed gasifiers. Biomass and Bioenergy 2013; 49: 279-289.

[25]Guo B, Li D, Cheng C, Lu Z, Shen Y. Simulation of biomass gasification with a hybrid neural network model. Bioresource Technology 2001; 76: 77-83.

[26] Mikulandric R, Loncar D, Bohning D, Bohme R, Beckmann M. Artificial neural network modelling approach for a biomass gasification process in fixed bed gasifiers. Energy Conversion and Management 2014; 87: $1210-23$. 
[27] Bui M, Gunawan I, Verheyen V, Feron P, Meuleman E, Adeloju S. Dynamic modelling and optimisation of flexible operation in post-combustion $\mathrm{CO}_{2}$ capture plants - A review. Computers and Chemical Engineering $2014 ; 61: 245-265$.

[28] Wang S, Xu X. Parameter estimation of internal mass of building dynamic models using genetic algorithm. Energy Conversion and Management 2006; 47: 1927-1941.

[29] Fendri D, Chaabene M. Dynamic modelt o follow the state of charge of lead-acid batery connected to photovoltaic panel. Energy Conversion and Management 2012; 64: 587-593.

[30] Vlachogianni A, Kassomenos P, Karppinen A, Karakitsios S, Kukkonen J. Evaluation of a multiple regression model for the forecasting of the concentrations of $\mathrm{NO}_{\mathrm{x}}$ and $\mathrm{PM}_{10}$ in Athens and Helsinki. Sceince of the Total Environment 2011; 409: 1559-1571.

[31] Boylan J, Russell A. PM and light extinction model performance metrics, goals, and criteria for threedimensional air quality models. Atmospheric Environment 2006; 40: 4946-4959. 
Table 1

Measurement methodology and equipment

\begin{tabular}{|c|c|}
\hline Process parameter & Measurement methodology and equipment \\
\hline Biomass mass flow rate & Manual weight measurement \\
\hline Air volume flow rate & Pressure difference based methodology (orifice plate) \\
\hline Syngas temperature at the exit of the gasifier & Measurement based on thermoelectric effect (thermocouple type $\mathrm{K}$ ) \\
\hline Syngas composition & $\mathrm{CO}, \mathrm{CH}_{4}, \mathrm{CO}_{2}$ - Non Dispersive Infrared Absorption methodology \\
& $\mathrm{H}_{2}-$ Thermal conductivity methodology \\
& O $\mathrm{O}_{2}$ - Electrochemical process \\
\hline Temperature of inlet air & Measurement based on platinum resistance effect (Pt 100) \\
\hline Pressure in the reactor & Wheatstone bridge circuit based measurement methodology (Piezoresistive strain \\
\hline & \\
\hline
\end{tabular}

Table 2

Average prediction error tolerance sensitivity analysis

\begin{tabular}{|c|c|c|c|}
\hline Error tolerance threshold & $\begin{array}{c}\text { Average prediction error for } \\
\text { Experiments 1-9 [\%] }\end{array}$ & $\begin{array}{c}\text { Number of re-training } \\
\text { sessions [-] }\end{array}$ & $\begin{array}{c}\text { Total time for re-training } \\
\text { [sec] }\end{array}$ \\
\hline $50 \%$ & 12.90 & 7 & 140 \\
\hline $40 \%$ & 11.66 & 8 & 150 \\
\hline $30 \%$ & 10.61 & 20 & 315 \\
\hline $20 \%$ & 8.38 & 26 & 410 \\
\hline $10 \%$ & 7.06 & & 12 \\
\hline
\end{tabular}

Table 3

Average prediction error tolerance analysis for different datasets sizes

\begin{tabular}{|c|c|c|c|}
\hline $\begin{array}{c}\text { Data available for } \\
\text { retraining [min] }\end{array}$ & $\begin{array}{c}\text { Average prediction error for } \\
\text { Experiments 1-9 [\%] }\end{array}$ & $\begin{array}{c}\text { Number of re-training } \\
\text { sessions [-] }\end{array}$ & $\begin{array}{c}\text { Total time for re-training } \\
\text { [sec] }\end{array}$ \\
\hline 1000 & 12.06 & 19 & 115 \\
\hline 1500 & 11.85 & 18 & 165 \\
\hline 2000 & 11.52 & 16 & 180 \\
\hline 2350 & 11.02 & 12 & 190 \\
\hline All data & 10.61 & 12 & 165 \\
\hline
\end{tabular}


Table 4

Average prediction error tolerance analysis for different datasets sizes

\begin{tabular}{|c|c|c|c|}
\hline Model type & $\begin{array}{c}\text { Average prediction error for } \\
\text { Experiments 1-9 [\%] }\end{array}$ & $\begin{array}{c}\text { Number of re-training } \\
\text { sessions [-] }\end{array}$ & $\begin{array}{c}\text { Total time for re-training } \\
\text { [sec] }\end{array}$ \\
\hline MLR1 & 9.93 & 13 & 9 \\
\hline MLR2 & 9.56 & 22 & 410 \\
\hline NNM & 7.06 & 26 & 10 \\
\hline
\end{tabular}

Table 5

Performance summary of the dynamic model for syngas composition prediction

\begin{tabular}{|c|c|c|c|}
\hline $\begin{array}{c}\text { Prediction parameters } \\
{[\%]}\end{array}$ & $\begin{array}{c}\text { Average prediction error for } \\
\text { Experiments 5-8 [\%] }\end{array}$ & $\begin{array}{c}\text { Number of re-training } \\
\text { sessions [-] }\end{array}$ & $\begin{array}{c}\text { Total time for re-training } \\
\text { [sec] }\end{array}$ \\
\hline $\mathrm{H}_{2}$ & 26.4 & 102 & 780 \\
\hline $\mathrm{CO}$ & 29.9 & 88 & 810 \\
\hline $\mathrm{CH}_{4}$ & 38.3 & 105 & 760 \\
\hline
\end{tabular}

\section{Table 6}

Statistical model performance analysis

\begin{tabular}{|c|c|c|c|c|c|}
\hline Model & $\mathbf{R}^{2}$ & RMSE & APE & MFB & MMBF \\
\hline Error tolerance threshold - 50\% & 0.74 & 45.07 & 0.13 & 0.0047 & -0.0204 \\
\hline Error tolerance threshold - 40\% & 0.78 & 41.71 & 0.12 & 0.0009 & -0.0136 \\
\hline Error tolerance threshold - 30\% & 0.80 & 39.47 & 0.11 & 0.0146 & 0.0023 \\
\hline Error tolerance threshold - 20\% & 0.87 & 31.13 & 0.08 & 0.0042 & -0.0098 \\
\hline Error tolerance threshold - 10\% & 0.82 & 24.79 & 0.07 & 0.0044 & 0.0029 \\
\hline Data available for retraining - 1000 & 0.78 & 41.37 & 0.12 & 0.0104 & 0.0016 \\
\hline Data available for retraining - 1500 & 0.79 & 40.52 & 0.12 & 0.0045 & -0.0072 \\
\hline Data available for retraining - 2000 & 0.80 & 39.80 & 0.12 & 0.0031 & -0.0039 \\
\hline Data available for retraining - 2350 & 0.83 & 39.77 & 0.11 & 0.0094 & -0.0194 \\
\hline Data available for retraining - All data & 0.82 & 39.46 & 0.11 & 0.0146 & 0.0023 \\
\hline MLR 1 & 0.81 & 38.39 & 0.10 & 0.0126 & 0.0067 \\
\hline MLR 2 & 0.80 & 39.64 & 0.10 & 0.0191 & -0.0191 \\
\hline CH & 0.47 & 195.37 & 0.26 & 0.0085 & -0.0323 \\
\hline CO & 0.83 & 276.83 & 0.30 & -0.004 & -0.0294 \\
\hline
\end{tabular}




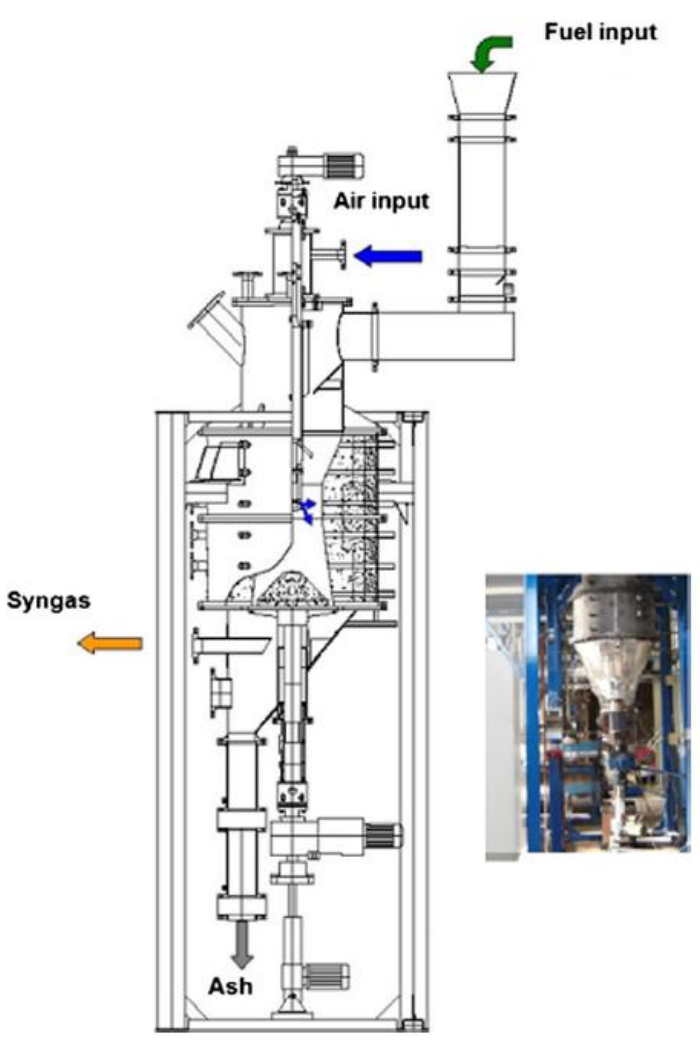

Fig 1. Scheme of co-current fixed bed biomass gasification facility operated by TU Dresden
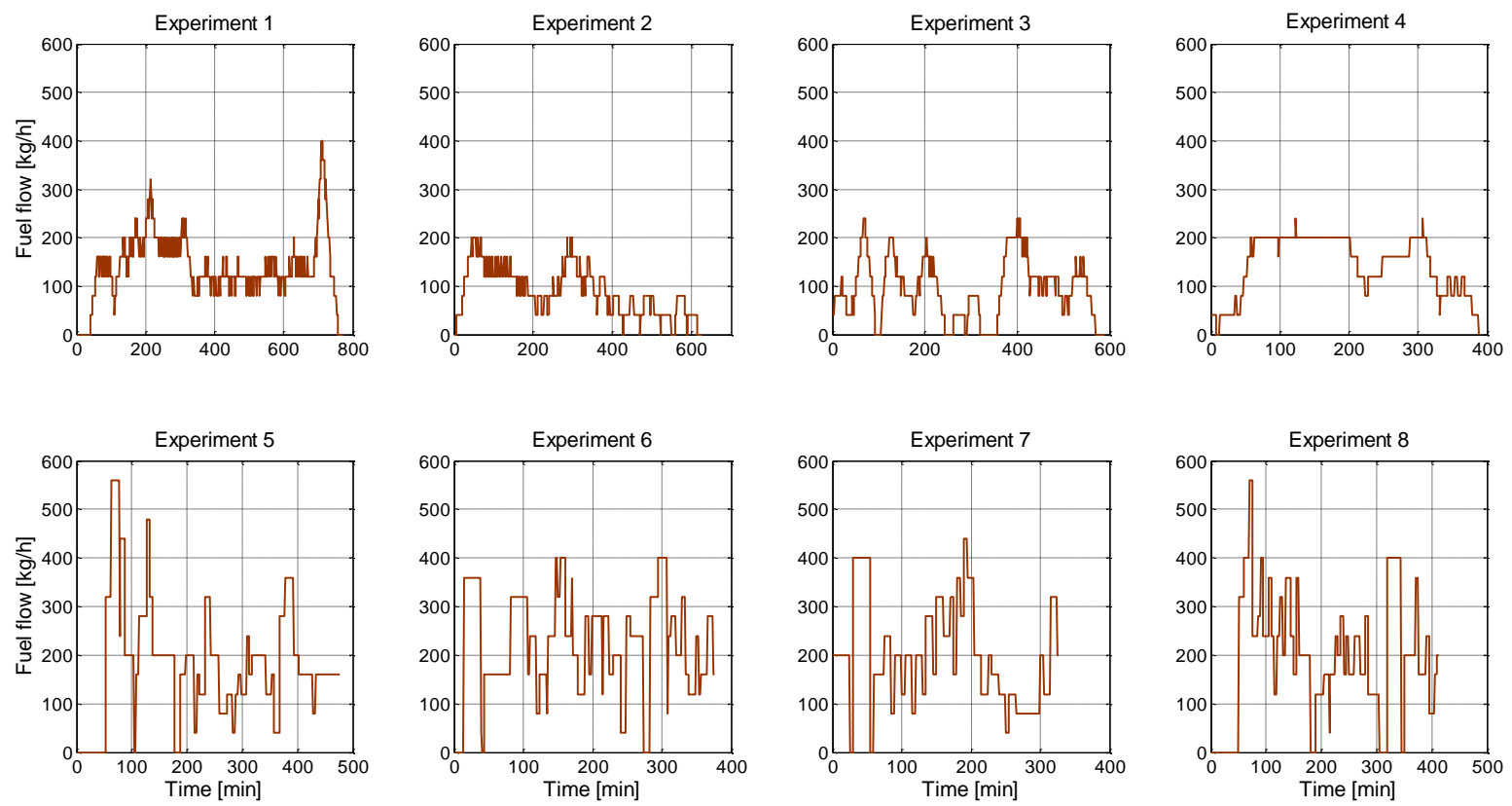

Figure 2. Average fuel flow rate for experiments 1-8 

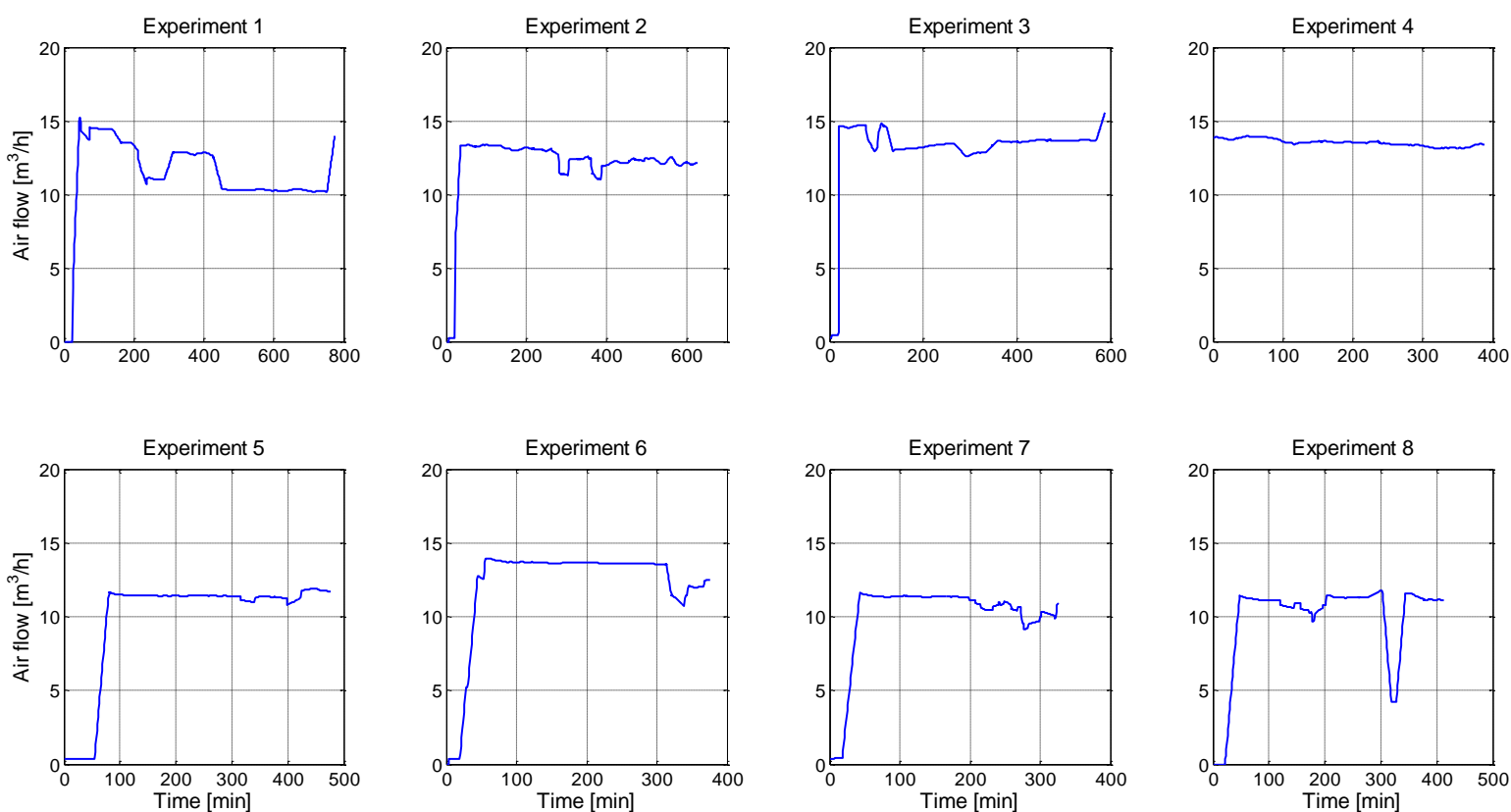

Figure 3. Average air flow rate for experiments 1-8
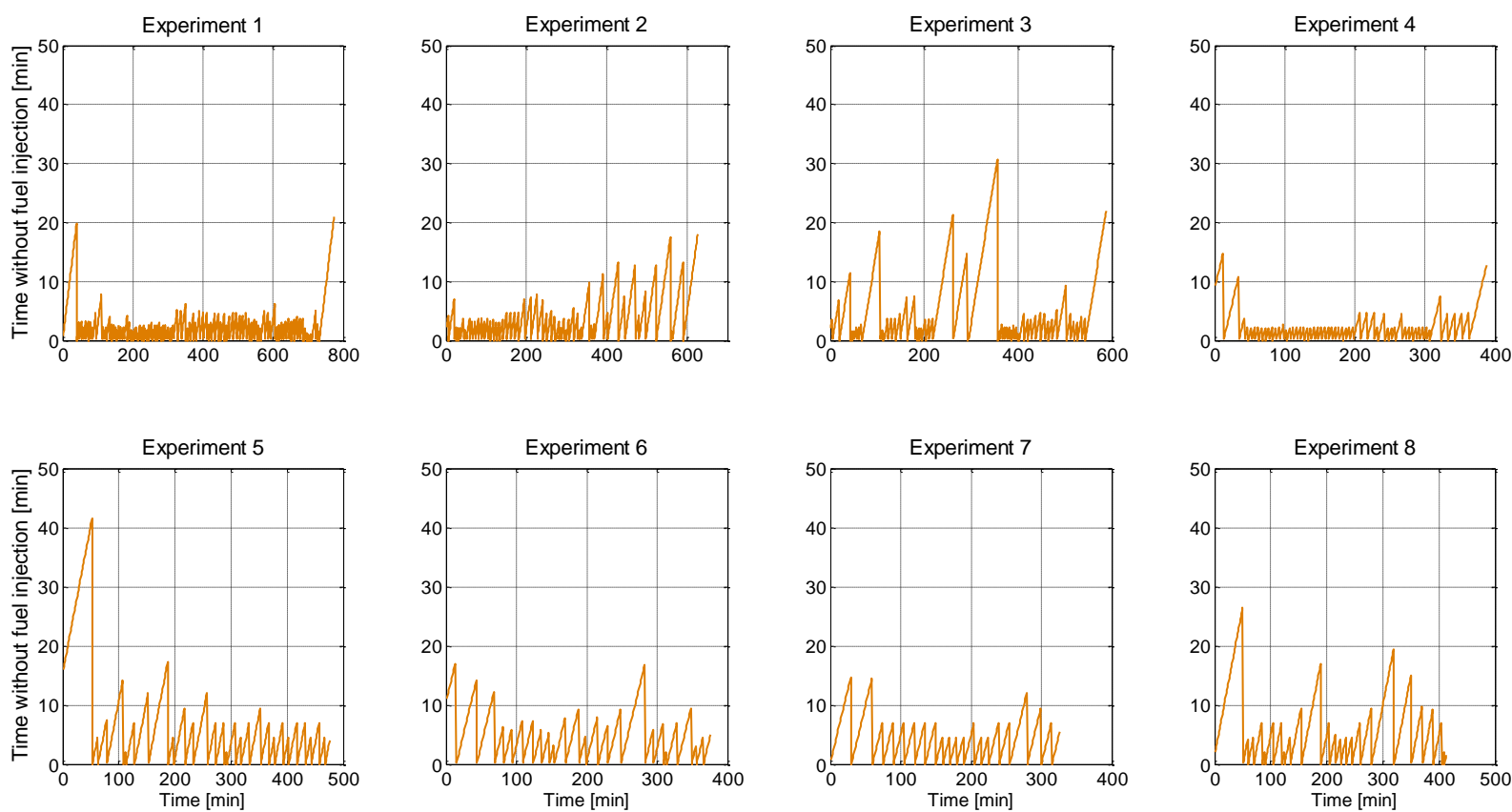

Figure 4. Time without fuel injection for experiments 1-8 


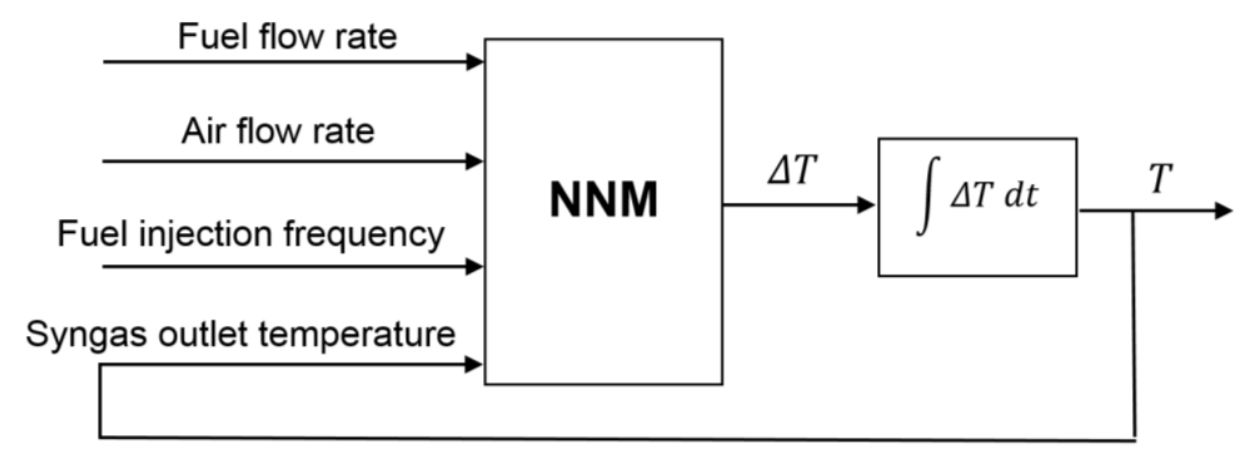

Figure 5. General scheme of artificial network based temperature prediction model

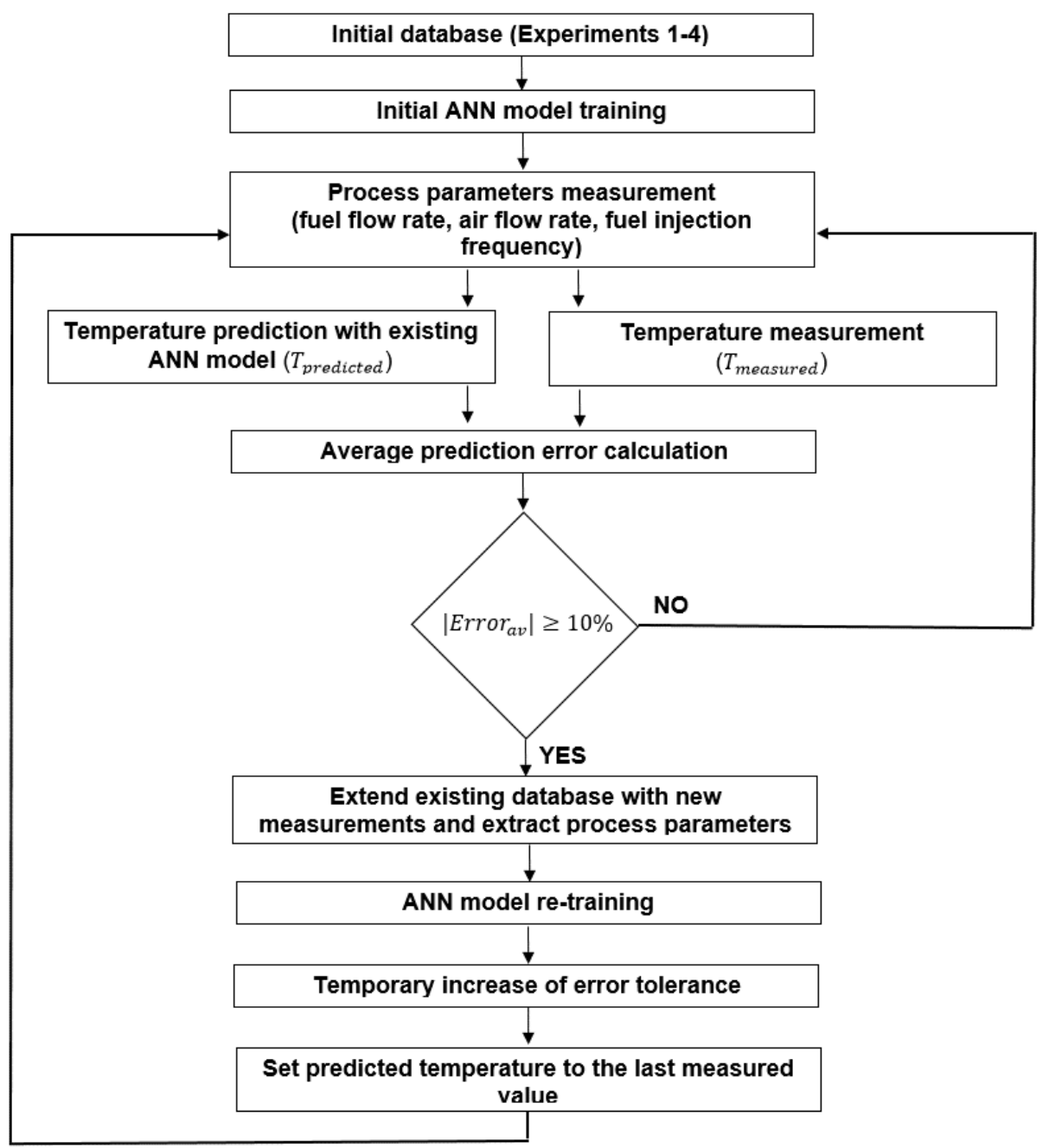

Figure 6. NNM modelling scheme with $10 \%$ of error tolerance threshold 

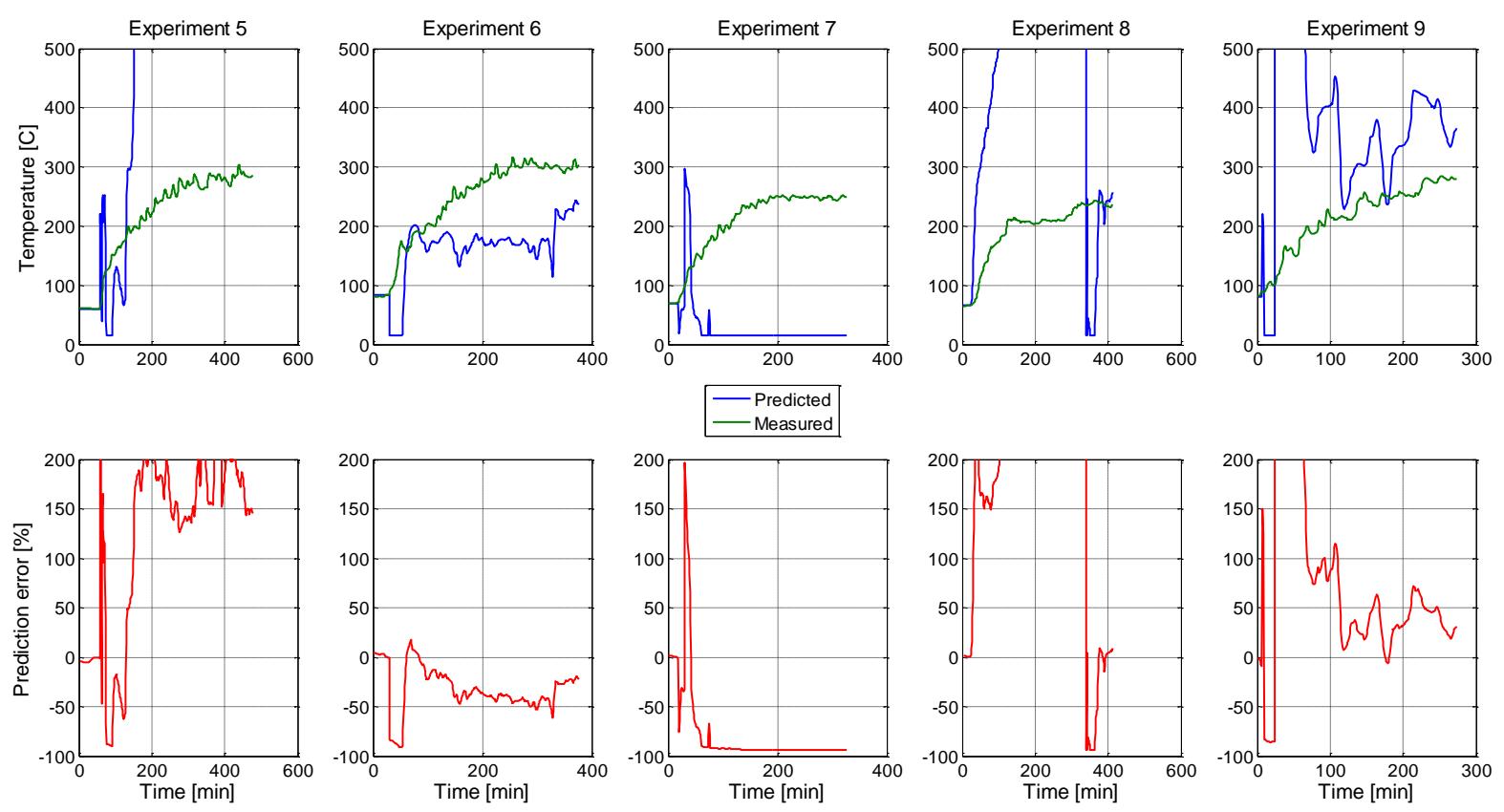

Figure 7. NNM prediction result with initial database from Experiments 1-4
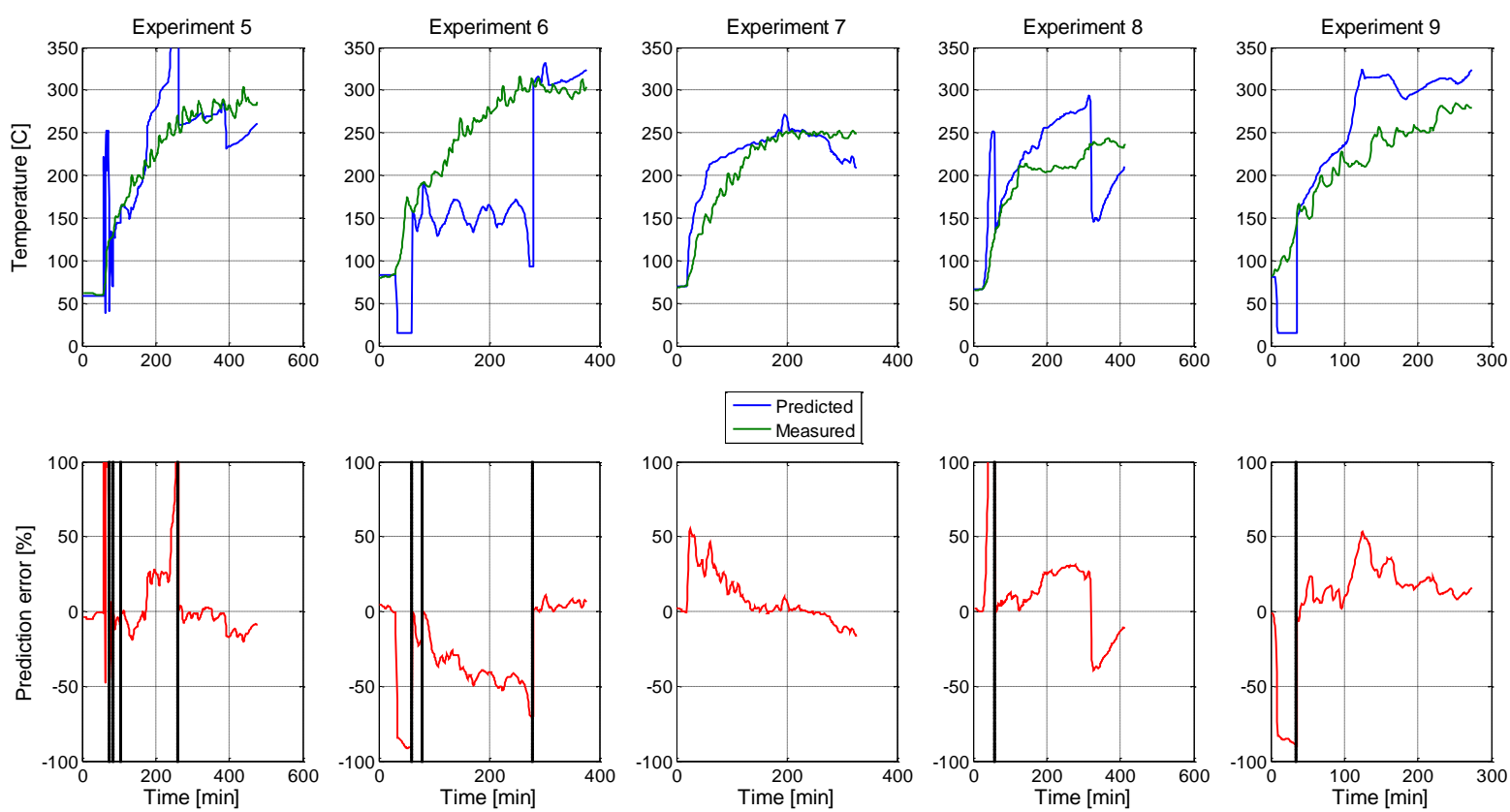

Figure 8. Dynamic NNM prediction result with $50 \%$ of error tolerance threshold 

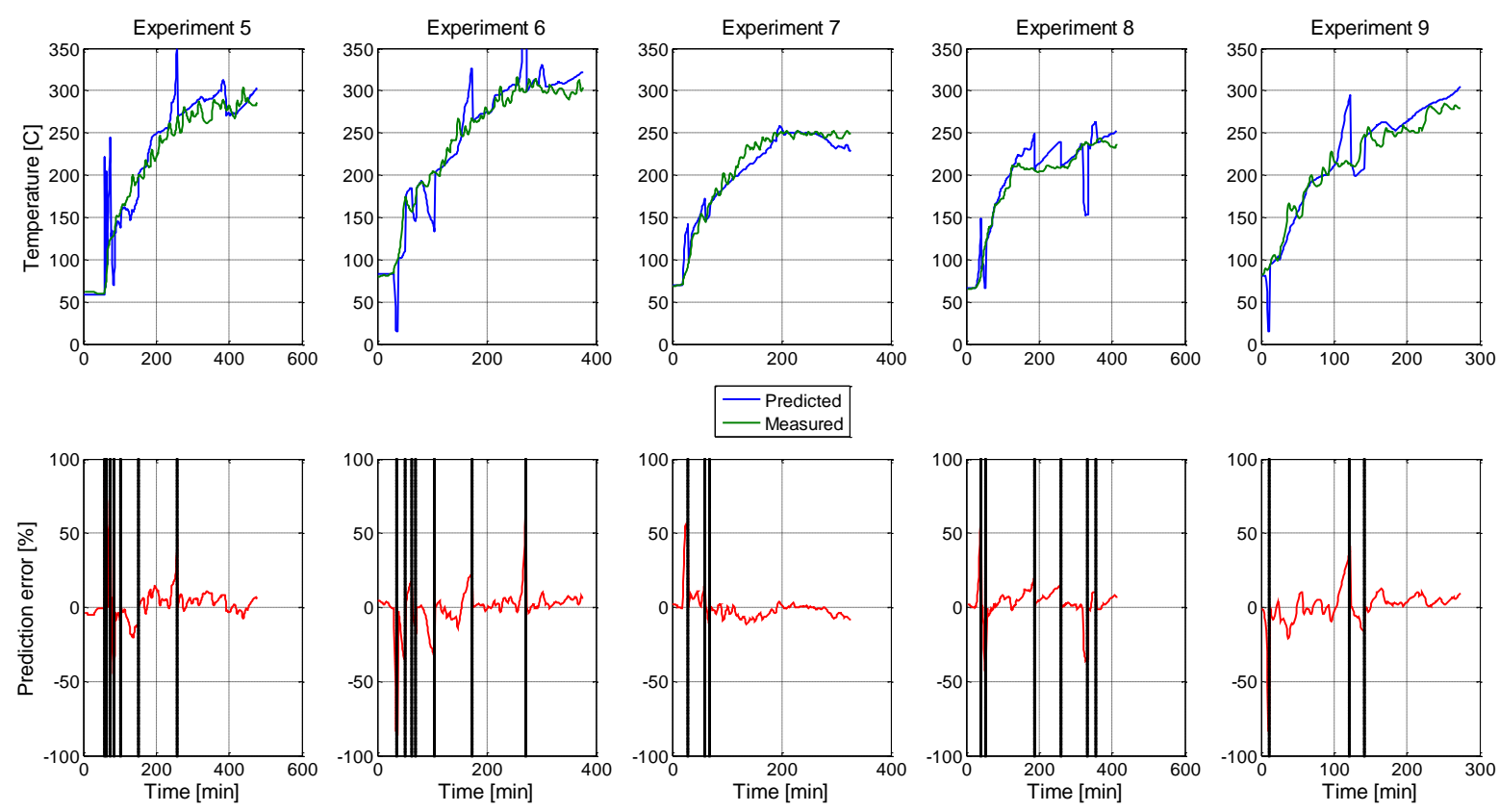

Figure 9. Dynamic NNM prediction results with $10 \%$ of error tolerance threshold 

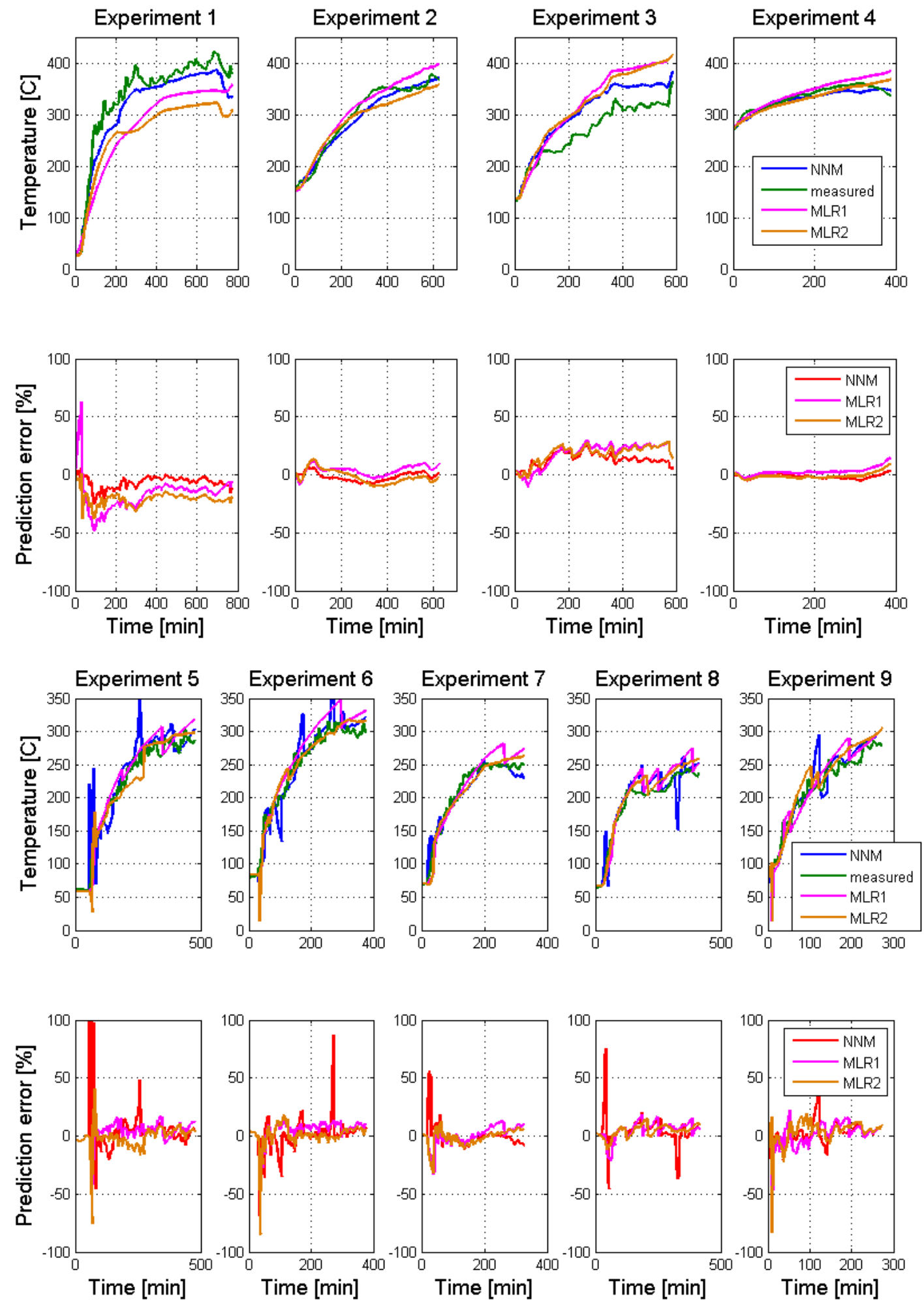

Figure 10. Detailed performance analysis of different dynamic modelling approaches 

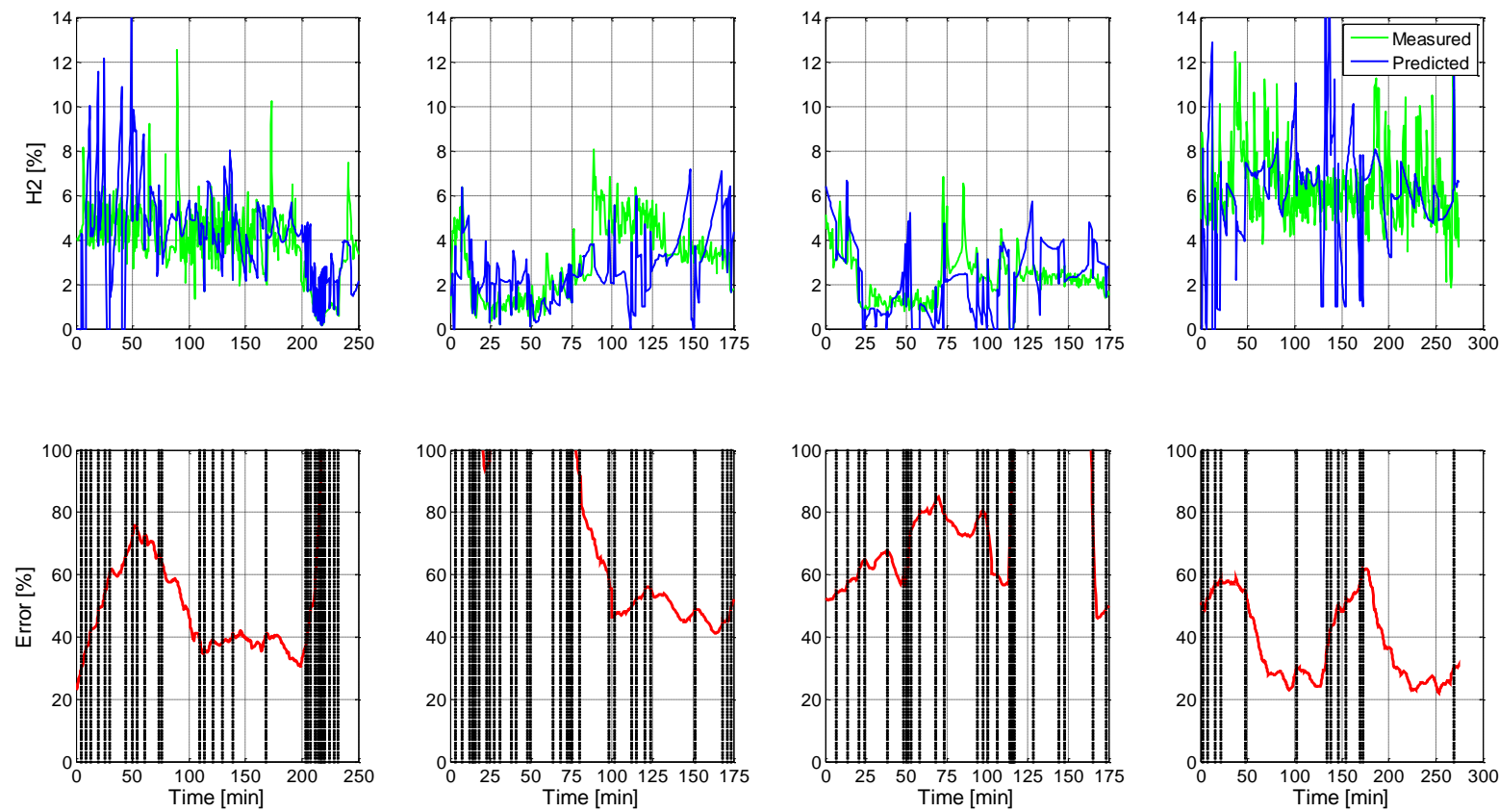

Figure 11. Dynamic NNM performance for $\mathrm{H}_{2}$ predictions (Experiments 5-8)
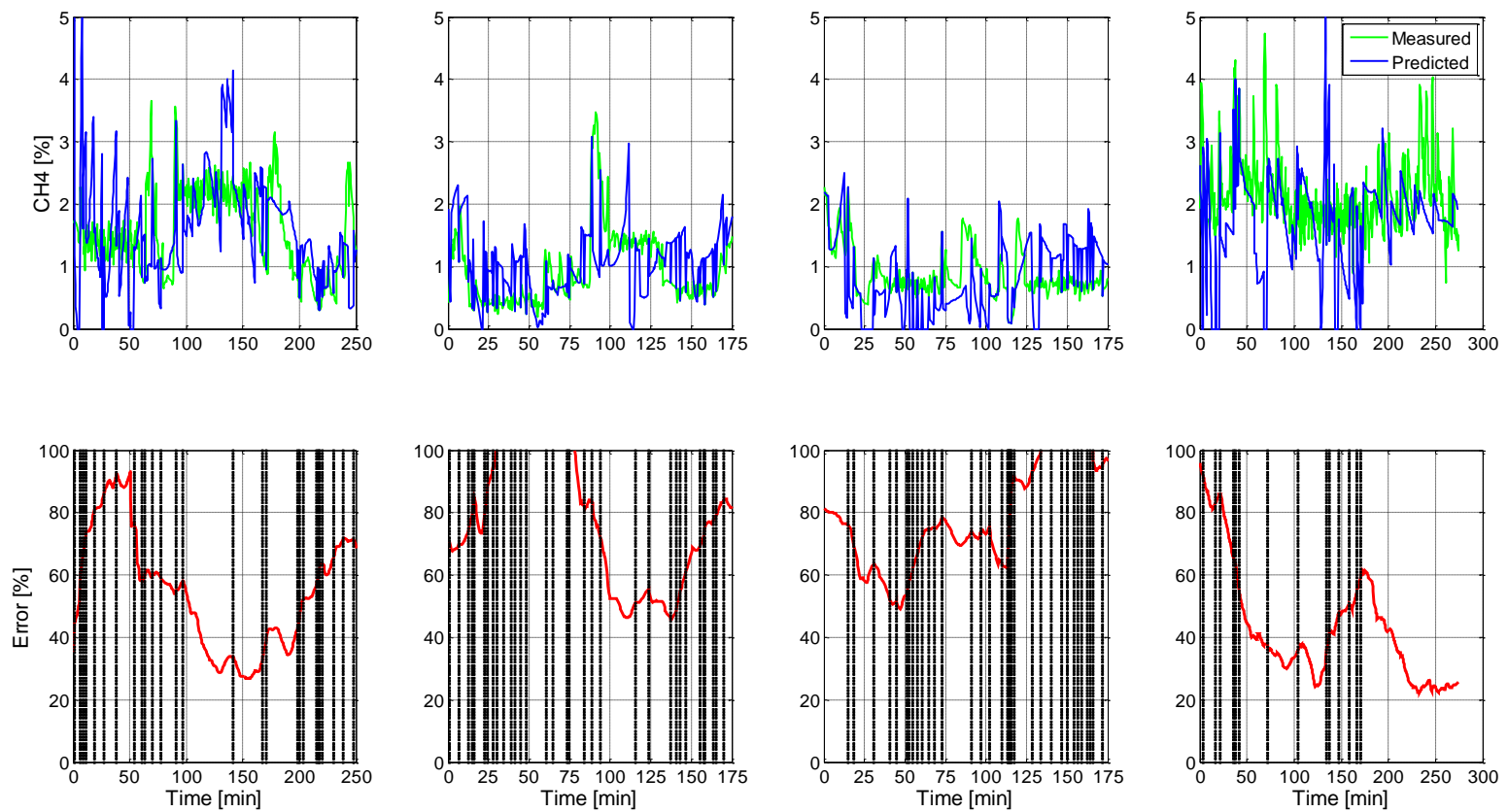

Figure 12. Dynamic NNM performance for $\mathrm{CH}_{4}$ predictions (Experiments 5-8) 

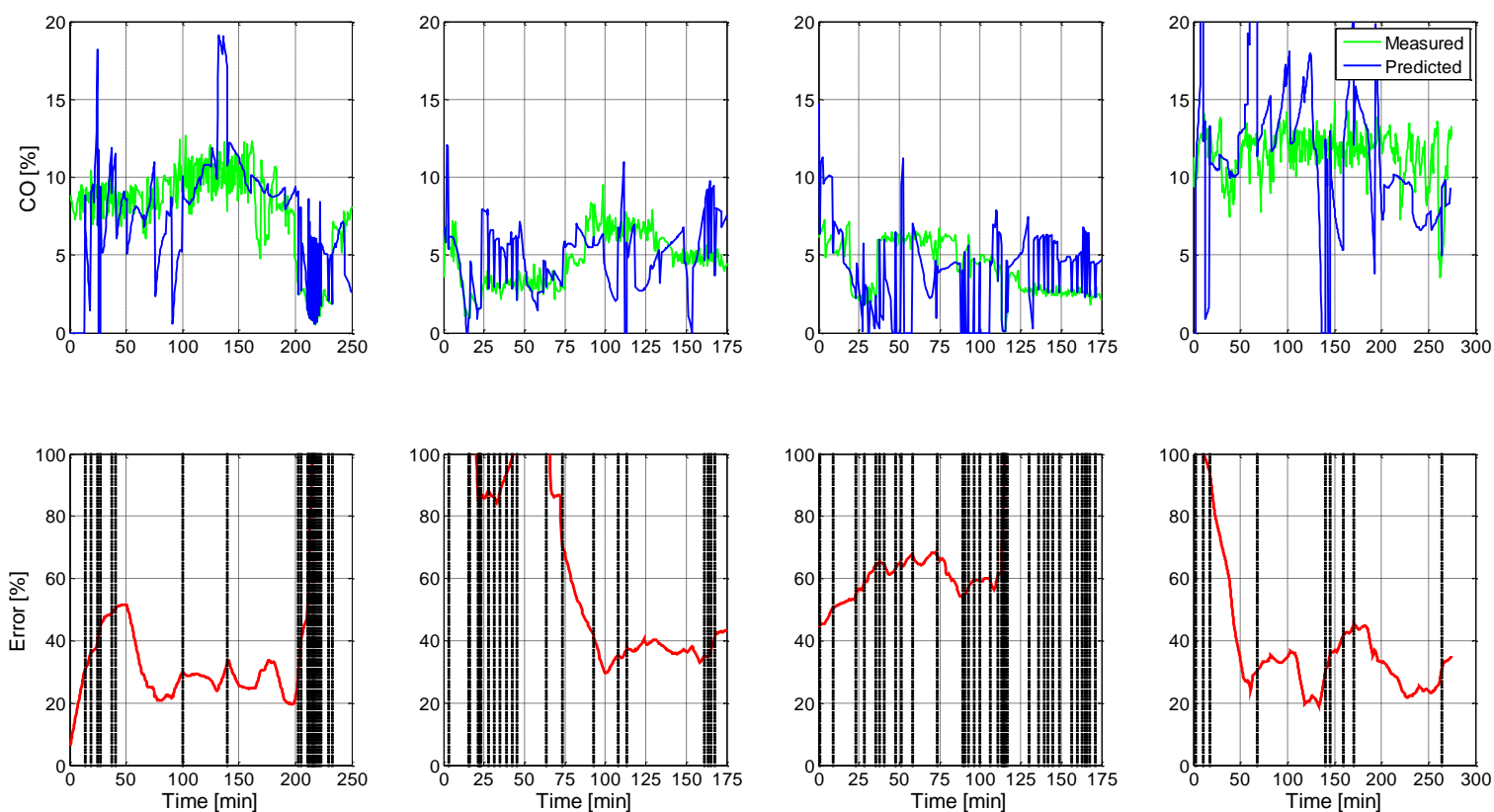

Figure 13. Dynamic NNM performance for CO predictions (Experiments 5-8) 